\title{
Non-Invasive Parameters of Oesophageal Varices Diagnosis: Which Sensitive and Applicable; A Pilot Study
}

\author{
Elham Ahmed Hassan ${ }^{1 *}$, Abeer Sharaf El-din Abd El-rehim ${ }^{1}$, Zain El-Abdeen Ahmed Sayed ${ }^{2}$, Emad Farah Mohamed Kholef ${ }^{3}$, Mostafa Abdullah Mohammed \\ Hareedy $^{2}$ and Refaat Fathy Abd EL-aal ${ }^{2}$ \\ ${ }^{1}$ Department of Tropical Medicine and Gastroenterology, Faculty of Medicine, Assiut University, Egypt \\ ${ }^{2}$ Department of Internal Medicine, Faculty of Medicine, Assiut University, Egypt \\ ${ }^{3}$ Department of Clinical Pathology, Faculty of Medicine, Aswan University, Egypt
}

${ }^{*}$ Corresponding Author: Elham Ahmed Hassan, Assiut University Hospital, Tropical Medicine and Gastroenterology, 6th floor, Assiut, Egypt, Tel: +201002963415; Fax: +20882333327; E-mail: mam_elham75@yahoo.com

Received July 08, 2015; Accepted July 10, 2015; Published July 13, 2015

Copyright: (C) 2015, Hassan EA, et al. This is an open-access article distributed under the terms of the Creative Commons Attribution License, which permits unrestricted use, distribution, and reproduction in any medium, provided the original author and source are credited.

\begin{abstract}
Background: Oesophageal varices (OV) have the greatest clinical impact. Upper endoscopy is the gold standard for OV diagnosis, despite its own limitations. Non-invasive detection of OV promises to decrease the necessity of endoscopic screening.
\end{abstract}

Objectives: To assess blood ammonia level, spleen longitudinal (SLD), portal vein (PVD), splenic vein (SVD) diameters, platelets count and platelets/SLD ratio to evaluate their predictive accuracy as non-invasive indicators for the presence of $\mathrm{OV}$ and their correlation with variceal size.

Patients and methods: This was a prospective study. Sixty cirrhotic patients were screened using upper endoscopy (for the presence and size of OV) and abdominal ultrasonography (for measurement of PVD, SVD, SLD). Fasting blood ammonia level, platelets / SLD ratio were measured.

Results: Blood ammonia, PVD, SVD and SLD were significantly higher in patients with OV than those without (P $<0.001$ for all). Using area under receiver operating characteristic curve (AUC), these parameters were good predictors for the presence of OV where, PVD had the highest AUC (I.00) followed by blood ammonia (AUC 0.99). Blood ammonia level correlated with variceal size (rho $=0.442, P=0.002$ ).

Conclusion: Blood ammonia, PVD, SVD and SLD were good non-invasive predictors for OV presence with the superiority of PVD and ammonia. Blood ammonia level could be clinically useful, as it correlated with the size of OV so, pinpoint those patients requiring closer follow-up and endoscopic screening.

Keywords: Oesophageal varices; Blood ammonia; Spleen longitudinal diameter; Portal vein diameter; Splenic vein diameter

\section{Introduction}

Oesophageal varices (OV), formed as a result of portal hypertension, have a great clinical impact due their severe complications [1]. While they are found in approximately $50 \%$ in cirrhosis, they are developed at a rate of $8 \%$ per year in patients without varices. The progression from small to large varices occurs in 10 to $20 \%$ of cases yearly and their presence correlates with the severity of liver disease [2]. Variceal hemorrhage develops at a yearly rate of 5 to $15 \%$, where the most important predictor of hemorrhage occurring with large varices $[3,4]$.

The American association for the study of liver disease single topic symposium stated that cirrhotic patients should be screened for the presence of $\mathrm{OV}$ when portal hypertension is diagnosed [5]. Upper gastrointestinal (GI) endoscopy is the gold standard in the diagnosis of OV. It had been suggested for endoscopy to be repeated at 2-3 years interval in patients without varices and at 1-2 years interval in patients with small varices to evaluate the development and / or progression of OV $[3,6]$.

However, this approach has some limitations as endoscopy is an invasive procedure, the cost-effectiveness is questionable, also, only $9 \%-36 \%$ of patients with cirrhosis found to have varices on screening endoscopy [7]. So, the possibility of non-invasive means for identifying cirrhotic patients with $\mathrm{OV}$ or collateral presence is appealing, in that it could decrease the necessity of endoscopic screening with reduced healthcare costs [1].

Several parameters have been discussed along previous studies with varying rate of success. They have either been based on laboratory parameters, i.e. platelets count (PLTS) or ultrasonographic (US) features [8-12]. Recent studies explained the role of blood ammonia level (BAL) in the pathogenesis of portosystemic collaterals (PSC). Actually, ammonia levels cannot serve as a laboratory marker for portosystemic encephalopathy, being neither specific nor highly sensitive [13], although there may be a correlation with severity [14].

Our study aimed to determine noninvasive parameters for identifying the presence of $\mathrm{OV}$, to compare the predictive accuracy of 
these parameters in the development of $\mathrm{OV}$ and to evaluate the correlation between them and variceal size.

\section{Patients and Methods}

\section{Study design}

This cross-sectional study was carried out prospectively at Assiut University Hospital (AUH), Egypt. The study was approved by the local Ethics Committee of AUH and was conducted in accordance with the previsions of the Declaration of Helsiniki. Informed consent was obtained from all the participants before enrollment.

\section{Patients}

Sixty cirrhotic patients were selected from inpatient department and outpatient clinic of Internal Medicine and Tropical Medicine and Gastroenterology departments at Assiut University Hospital. All patients met the diagnostic criteria of liver cirrhosis by clinical, biochemical and ultrasonographic findings. The selected patients were of Child "A" and early "B" according to Child-Pugh scoring system [15].

These patients were divided into:

- 40 patients with evidence of esophageal varices by upper gastrointestinal endoscopy with or without abdominal portosystemic collaterals by abdominal ultrasound and

- 20 patients with neither evidence of varices (oesophageal or gastric) by upper gastrointestinal endoscopy nor portosystemic collaterals by abdominal ultrasound.

Exclusion criteria were patients who received endoscopic variceal ligation or sclerotherapy or beta blockers, presence of hepatic encephalopathy, active bleeding varices, chronic infection, hepatocellular carcinoma, portal vein thrombosis, renal insufficiency and blood disease.

\section{All patients were subjected to the following:}

- Thorough medical history and clinical examination

- Liver function tests; Aspartate aminotransferase (AST), alanine aminotransferase (ALT), albumin, bilirubin and prothrombin time.

- Renal function tests: serum creatinine and blood urea nitrogen.

- Complete blood count including platelet count

- Fasting blood ammonia level (BAL).

- Abdominal ultrasonography to see size of liver and spleen, HCC, portal, splenic vein and longitudinal spleen (SPD) diameters, portal vein thrombosis, portosystemic collaterals and ascites.

- Upper gastrointestinal endoscopy to detect the presence of oesophageal and gastric varices, their size and number, and evidence of portal hypertensive gastropathy.

\section{Methods}

After avoidance of factors that may affect blood ammonia level (BAL), $5 \mathrm{ml}$ of venous blood was taken in the morning and at complete rest from fasting patients. Blood samples were collected in tubes containing ethylene-diamine-tetraacetic acid (EDETA) and analyzed within 30 minutes of collection. BAL was estimated by enzymatic UV-method using the glutamate dehydrogenase reaction (GLDH-UV) with reagents obtained from (Greiner Diagnostic GmbH
-Unter Gereuth 10 - D-79353 Bahlingen - Germany) according to the manufacturer's protocol.

\begin{tabular}{|c|c|c|}
\hline & $\begin{array}{l}\text { Patients with OV } \\
(n=40)\end{array}$ & $\begin{array}{l}\text { Patients without OV } \\
(n=20)\end{array}$ \\
\hline Age (years, mean $\pm S D$ ) & $52.2 \pm 6.4$ & $50.3 \pm 6.1$ \\
\hline \multicolumn{3}{|l|}{$\operatorname{Sex}(n)$} \\
\hline Male & 34 (85\%) & 11 (55\%) \\
\hline Female & $6(15 \%)$ & $9(45 \%)$ \\
\hline Jaundice (n) & $23(57.5 \%)$ & $4(20)$ \\
\hline Dilated abdominal veins $(n)$ & $5(2 \%)$ & 0 \\
\hline Hepatomegaly (n) & $32(80 \%)$ & $6(30 \%)$ \\
\hline Splenomegaly ( $n$ ) & $37(92.5 \%)$ & $8(40 \%)$ \\
\hline Ascites (n) & $3(7.5 \%)$ & 0 \\
\hline LPSS (n) & $20(50 \%)$ & 0 \\
\hline $\mathrm{Hb}(\mathrm{gm} / \mathrm{dl}$, mean $\pm \mathrm{SD})$ & $9.7 \pm 1.3$ & $9.9 \pm 1.6$ \\
\hline WBCs (X103/dl, mean \pm SD) & $4.9 \pm 1.7$ & $5.5 \pm 2$ \\
\hline PLT (X103/dl, mean \pm SD) & $75.9 \pm 17.4$ & $76.3 \pm 21.2$ \\
\hline AST (IU/L, mean $\pm S D)$ & $72.4 \pm 25.1$ & $78.1 \pm 34$ \\
\hline ALT (IU/L, mean $\pm S D)$ & $77.8 \pm 22.2$ & $71.9 \pm 18.1$ \\
\hline $\begin{array}{l}\text { Serum Albumin (gm/dl, mean } \pm \\
\text { SD) }\end{array}$ & $2.9 \pm 0.2$ & $3 \pm 0.2$ \\
\hline Total bilirubin $(\mathrm{mg} / \mathrm{dl}$, mean $\pm \mathrm{SD})$ & $2.1 \pm 0.3$ & $1.6 \pm 0.3$ \\
\hline INR (mean \pm SD) & $1.4 \pm 0.1$ & $1.3 \pm 0.13$ \\
\hline Gastric varices $(n)$ & 7 & 0 \\
\hline PHG (n) & 32 & 0 \\
\hline \multicolumn{3}{|c|}{$\begin{array}{l}\text { OV: Oesophageal Varices; LPSS: Large Spontaneous Shunts; Hb: Hemoglobin; } \\
\text { WBCs: White Blood Cells; PLT: Platelet Count; AST: Aspartate } \\
\text { Aminotransferase; ALT: Alanine Aminotransferase; INR: International } \\
\text { Normalization Ratio; PHG: Portal Hypertensive Gastropathy }\end{array}$} \\
\hline
\end{tabular}

Table 1: Demographic, clinical and laboratory characteristics of the study population.

\section{Statistical analysis}

All statistical analyses were conducted using Statistical Package for the Social Sciences (SPSS) for Windows version 17 (SPSS Inc., Chicago, IL, USA). The quantitative data were expressed as mean \pm standard deviation (SD) and were compared using Student's t-test. Qualitative data were expressed as percentage and compared using the chi-squared or Fisher's exact (two-tailed) test. The area under receiver operating characteristic curve (AUC) curves were plotted to measure and compare the performance of different non-invasive parameters in predicting presence of $\mathrm{OV}$ and to select the best cut-off value with the highest accuracy (by calculating the sensitivity, specificity, positive $(\mathrm{PPV})$ and negative predictive values (NPV) positive likelihood ratio $(+\mathrm{LR})$ for predicting or excluding OV. The relation between these parameters and size of OV was analyzed with the Spearman's 
Citation: Hassan EA, El-rehim ASEA,Sayed ZEA, Kholef EFD, Hareedy MAM et al. (2015) Non-Invasive Parameters of Oesophageal Varices Diagnosis: Which Sensitive and Applicable; A Pilot Study. J Liver 4: 182. doi:10.4172/2167-0889.1000182

Page 3 of 5

correlation coefficient test. For all analyses, p value $<0.05$ was considered statistically significant.

\section{Results}

The baseline sociodemographic clinical and biochemical characteristics of the study patients were summarized in Table 1 . The study included 60 patients with liver cirrhosis; 45 males (75\%) and 15 females $(25 \%)$ with mean age of $51.3 \pm 6.3$ years.

Table 2 showed that non-invasive parameters; blood ammonia level (BAL), spleen longitudinal diameter (SLD), portal vein diameter (PVD) and splenic vein diameter (PVD) were significantly higher means in patients with $\mathrm{OV}$ than patients without (P value $<0.001$ for all). However, platelet count and platelet / SLD ratio, ALT, AST showed no significant differences between patients with and without $\mathrm{OV}$ ( $\mathrm{P}$ value $>0.05)$.

\begin{tabular}{|c|c|c|c|}
\hline $\begin{array}{l}\text { non-invasive parameters } \\
\text { (mean } \pm \text { SD) }\end{array}$ & $\begin{array}{l}\text { Patients with } \\
\text { OV }(n=40)\end{array}$ & $\begin{array}{l}\text { Patients without } \\
\text { OV }(n=20)\end{array}$ & $P$ value \\
\hline Blood ammonia $(\mu \mathrm{mol} / \mathrm{L})$ & $108.5 \pm 32$ & $50 \pm 12$ & $<0.001$ \\
\hline $\begin{array}{l}\text { Spleen longitudinal diameter } \\
(\mathrm{cm})\end{array}$ & $16.1 \pm 1.4$ & $13.5 \pm 1.6$ & $<0.001$ \\
\hline Portal vein diameter $(\mathrm{mm})$ & $15.5 \pm 1.3$ & $10.4 \pm 1.3$ & $<0.001$ \\
\hline Splenic vein diameter $(\mathrm{mm})$ & $10.6 \pm 1.4$ & $8.2 \pm 0.5$ & $<0.001$ \\
\hline Platelet count (X103/dl) & $75.9 \pm 17.4$ & $76.3 \pm 21.2$ & 0.245 \\
\hline Platelet / SLD ratio & $4.7 \pm 0.8$ & $5.7 \pm 1.2$ & 0.231 \\
\hline AST $(I U / L$, mean $\pm S D)$ & $72.4 \pm 25.1$ & $78.1 \pm 34$ & 0.499 \\
\hline $\mathrm{ALT}(\mathrm{IU} / \mathrm{L}$, mean $\pm \mathrm{SD})$ & $77.8 \pm 22.2$ & $71.9 \pm 18.1$ & 0.142 \\
\hline
\end{tabular}

OV: Oesophageal Varices; SLD: Spleen Longitudinal Diameter; AST: Aspartate aminotransferase; ALT: Alanine Aminotransferase

Table 2: Comparison between patients with oesophageal varices and patients without regarding non-invasive markers.

The receiver operating characteristic (ROC) curve was done for blood ammonia level, SLD, PVD and SVD for the prediction of OV where it revealed that the PVD yielded the highest AUC (1.00), followed by the blood ammonia level (AUC $=0.99,95 \%$ confidence interval $(\mathrm{CI})=0.99-1), \operatorname{SVD}(\mathrm{AUC}=0.96,95 \% \mathrm{CI}=0.94-1)$ and SLD (AUC $=0.77,95 \% \mathrm{CI}=0.64-0.91$ ) with $\mathrm{P}<0.001$ (for all), so all these variables were considered statistically significant (Figure 1).

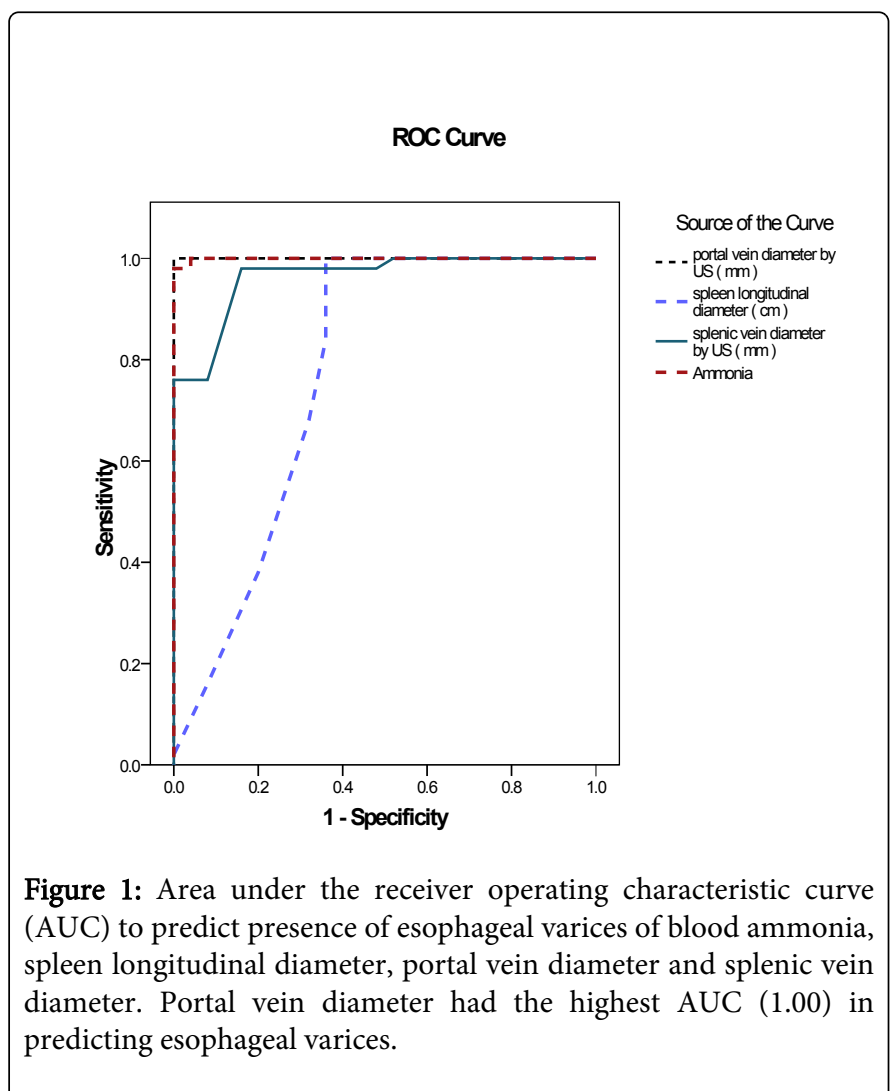

The optimum cut-off values of the previously mentioned parameters to predict the presence of $\mathrm{OV}$ were illustrated in Table 3 where; PVD $(13 \mathrm{~mm})$ and BAL $(65 \mu \mathrm{mol} / \mathrm{L})$ showed the highest diagnostic indices followed by SLD $(13.1 \mathrm{~cm})$ and SVD $(8.8 \mathrm{~mm})$. All showed acceptable sensitivity (100\% for all except $98 \%$ for SVD) and acceptable diagnostic accuracies (100\%, 98\%, 88\%, and $82.3 \%$ respectively), blood ammonia showed higher $(+\mathrm{LR})$ so it is ideal predictor for the presence of OV.

\begin{tabular}{|l|l|l|l|l|l|l|}
\hline & Sensitivity (\%) & Specificity (\%) & PPV (\%) & NPV (\%) & LR+ & Accuracy (\%) \\
\hline Portal vein diameter (13 mm) & 100 & 100 & 100 & 100 & - & 100 \\
\hline Blood ammonia level $(65 \mu \mathrm{mol} / \mathrm{L})$ & 100 & 95 & 97.6 & 100 & 20 & 98 \\
\hline Spleen long diameter (13.1 cm) & 100 & 65 & 85.1 & 100 & 2.9 & 88 \\
\hline Splenic vein diameter (8.8 mm) & 97 & 82 & 91.5 & 93.2 & 5.4 & 82.3 \\
\hline PPV: Positive Predictive Value; NPV: Negative Predictive Value; LR+: Positive Likelihood Ratio & & & \\
\hline
\end{tabular}

Table 3: Sensitivity, specificity, PPV, NPV LR+ and accuracy at optimum cut-off values of non-invasive parameters in predicting oesophageal varices.

Among different non-invasive parameters, only BAL positively correlated with the size of $\mathrm{OV}(\mathrm{r}=0.442, \mathrm{P}=0.002$, Table 4$)$. 


\begin{tabular}{|l|l|l|}
\hline Non-invasive parameters & Rho & P value \\
\hline Blood ammonia level & 0.442 & 0.002 \\
\hline Spleen longitudinal diameter & 0.121 & 0.43 \\
\hline Portal vein diameter & 0.103 & 0.44 \\
\hline Splenic vein diameter & 0.132 & 0.31 \\
\hline Platelet count & -0.11 & 0.52 \\
\hline Platelet /SLD ratio & -0.11 & 0.47 \\
\hline AST & 0.102 & 0.45 \\
\hline ALT & 0.11 & 0.51 \\
\hline
\end{tabular}

SLD: Spleen longitudinal diameter; AST: Aspartate aminotransferase; ALT: alanine aminotransferase

Table 4: Correlation of non-invasive parameters and size of oesophageal varices.

\section{Discussion}

Oesophageal varices (OV) are the most relevant portosystemic collaterals (PSCs) and have the greatest clinical impact where variceal hemorrhage is associated with higher morbidity, mortality and hospital costs than other causes of upper gastrointestinal tract bleeding $[16,17]$.

Our study assessed different non-invasive parameters to elaborate the reliable method to predict the presence of OV and their correlation with the variceal size.

The present work showed that blood ammonia level (BAL) was significantly higher in patients with OV than those without, where, BAL above $65 \mu \mathrm{mol} / \mathrm{L}$ can predict the presence of OV with $100 \%$ sensitivity, 95\% specificity and 97.6\% PPV. These results agreed with Tarantino et al., [1] who found that BAL more than $71 \mu \mathrm{mol} / \mathrm{L}$ had $97 \%$ sensitivity and $73 \%$ specificity for prediction of presence of portosystemic shunts. In addition, Khondaker et al., [18] revealed that blood ammonia at $63 \mu \mathrm{mol} / \mathrm{L}$ had $95 \%$ sensitivity and $50 \%$ specificity in detecting large OV in cirrhotics suggesting its usefulness in identifying patients with large varices who need endoscopy.

Our findings were consistent with Schepis et al. [19] and Cottone et al. [20], as we revealed that PVD is an independent factor for prediction of the presence of $\mathrm{OV}$, as patients with $\mathrm{OV}$ showed statistically significant higher mean of PVD in comparison to patients without varices. Also, PVD $\geq 13 \mathrm{~mm}$ had $100 \%$ sensitivity in predication of OV. Unlike Sarwar et al. [21] who postulated that PVD $>11 \mathrm{~mm}$ on ultrasonography is independently associated with the presence with OV.

Spleen longitudinal diameter (SLD) had significantly higher mean in patients with $\mathrm{OV}$ in comparison to patients without varices. SLD $\geq$ $13.1 \mathrm{~cm}$ had $100 \%$ sensitivity and $65 \%$ specificity for the prediction of the presence of OV. These findings agreed with Thomopoulos et al. [22] who proved that SLD of $13.5 \mathrm{~cm}$ or more has $95 \%$ sensitivity and $37 \%$ specificity in prediction of the presence of OV so, it can be considered as a good predictor for the presence of varices.

The current study showed that SVD was significantly wider in patients with OV than those without. SVD of $8.8 \mathrm{~mm}$ or more was a good predictor for the presence of OV with $97 \%$ sensitivity and $82 \%$ specificity. This was matched to findings of Montasser et al. [23] who found that splenic vein diameter $\geq 8.9 \mathrm{~mm}$ can predict the presence of OV in cirrhotics with $98 \%$ sensitivity and $84 \%$ specificity.

In agreement with Qamar et al. [24], platelets and platelets / splenic longitudinal diameter (PLT/SLD) ratio did not show significant difference in patients with and without OV suggesting that these markers cannot predict the presence of varices. However, this finding was in contrast to several studies done by Tarantino et al. [1] and Zaman et al. [9]. In this work, patients of Child "A" and early "B" liver cirrhosis had less impairment of platelet count which may explain this conflict.

Among these non-invasive parameters, only BAL positively correlated with the size of OV. This finding was comparable with that reported by Tarantino et al., [1] where $\mathrm{r}=0.43$ and $\mathrm{P}$ value was $<0.001$. On the other hand, our results were consistent with previous studies reported that the other markers did not show any correlation with the size of varices [18].

This study was a single-center and limited to patients with early liver cirrhosis. In addition, our findings are needed to be confirmed by further multicenter studies and to determine whether these parameters will be of benefit for the more severely affected patients who are unable to do endoscopic screening.

In conclusion, BAL, PVD, SVD and SLD were good non-invasive predictors for the presence of $\mathrm{OV}$ in cirrhotics with the superiority of PVD and ammonia. BAL could be a good tool to identify patients with large oesophageal varices, so, pinpoint those patients requiring closer follow-up and endoscopic screening.

\section{Conflicts of interest}

The authors declared that they had no conflicts of interest concerning this article.

\section{References}

1. Tarantino G, Citro V, Esposito P, Giaquinto S, de Leone A, et al. (2009) Blood ammonia levels in liver cirrhosis: a clue for the presence of portosystemic collateral veins. BMC Gastroenterol 9: 21.

2. Groszmann RJ, Garcia-Tsao G, Bosch J, Grace ND, Burroughs AK, et al. (2005) Portal Hypertension Collaborative Group. Beta-blockers to prevent gastroesophageal varices in patients with cirrhosis. N Engl J Med 353: 2254-2261.

3. Calès P, Desmorat H, Vinel JP, Caucanas JP, Ravaud A, et al. (1990) Incidence of large oesophageal varices in patients with cirrhosis: application to prophylaxis of first bleeding. Gut 31: 1298-12302.

4. North Italian Endoscopic Club for the Study and Treatment of Esophageal Varices (1988) Prediction of the first variceal hemorrhage in patients with cirrhosis of the liver and esophageal varices. A prospective multicenter study. N Engl J Med 319: 983-989.

5. Grace N, Groszmann R, Garcia-Tsao G, Burroughs AK, Pagliaro L, et al. (1998) Portal hypertension and variceal bleeding: An AASLD single topic symposium. Hepatology 28: 868-880.

6. D'Amico G, Pagliaro L, Bosch J (1998) The treatment of portal hypertension: A meta- analytic review. Hepatology 22: 332-354.

7. Spiegel BM, Targownik L, Dulai GS, Karsan HA, Gralnek IM (2003) Endoscopic screening for esophageal varices in cirrhosis: Is it ever cost effective? Hepatology 37: 366-377.

8. Chalasani N, Imperiale TF, Ismail A, Sood G, Carey M, et al (1999) Predictors of large esophageal varices in patients with cirrhosis. Am J Gastroenterol 94: 3285-3291. 
Citation: Hassan EA, El-rehim ASEA,Sayed ZEA, Kholef EFD, Hareedy MAM et al. (2015) Non-Invasive Parameters of Oesophageal Varices Diagnosis: Which Sensitive and Applicable; A Pilot Study. J Liver 4: 182. doi:10.4172/2167-0889.1000182

Page 5 of 5

9. Zaman A, Hapke R, Flora K, Rosen HR, Benner K (1999) Factor predicting the presence of esophageal or gastric varices in patients with advanced liver disease. Am J Gastroenterol 94: 3292-3296.

10. Madhotra R, Mulcahy HE, Willner I, Reuben A (2002) Prediction of esophageal varices in patients with cirrhosis. J Clin Gastroenterol 34: 81-85.

11. Giannini EG, Zaman A, Kreil A, Floreani A, Dulbecco P, et al. (2006) Platelet count/spleen diameter ratio for the noninvasive diagnosis of esophageal varices: results of a multicenter, prospective, validation study. Am J Gastroenterol 101: 2511-2519.

12. Alempijevic T, Bulat V, Djuranovic S, Kovacevic N, Jesic R, et al (2007) Right liver lobe/albumin ratio: Contribution to non-invasive assessment of portal hypertension. World J Gastroenterol 13: 5331-5335.

13. Nicolao F, Efrati C, Masini A, Merli M, Attili AF, et al. (2003) Role of determination of partial pressure of ammonia in cirrhotic patients with and without hepatic encephalopathy. J Hepatol 38: 441-446.

14. Ong JP, Aggarwal A, Krieger D, Easley KA, Karafa MT, et al. (2003) Correlation between ammonia levels and the severity of hepatic encephalopathy. Am J Med 114: 188-193.

15. Pugh RN, Murray-Lyon IM, Dawson JL, Pietroni MC, Williams R (1973) Transection of the oesophagus for bleeding oesophageal varices. Br J Surg 60: 646-649.

16. Sharara AI, Rockey DC (2001) Gastroesophageal variceal hemorrhage. N Engl J Med 345: 669-681.

17. Burroughs AK (1993). The natural history of varices. J Hepatol 17(Suppl): S10-13.
18. Khondaker MFA, Ahmed N, Al-Mahtab M, Sumi SA (2013) Correlation between blood ammonia level and esophageal varices in patients with cirrhosis of liver. Euroasian J Hepato-Gastroentrol 3: 10-14.

19. Schepis F, Cammà C, Niceforo D, Magnano A, Pallio S, et al. ( 2001) Which Patients with Cirrhosis Should Undergo Endoscopic Screening for Esophageal Varices Detection? Hepatology 33: 333-338.

20. Cottone M, D'Amico G, Maringhini A, Amuso M, Sciarrino E, et al. (1986) Predictive Value of Ultrasonography in the Screening of NonAscitic Cirrhotic Patients with Large Varices. Journal of Ultrasound in Medicine 5: 189-192.

21. Sarwar S, Khan AA, Alam A, Butt AK, Shafqat F, et al. (2005) NonEndoscopic Prediction of Presence of Esophageal Varices in Cirrhosis. J Coll Physicians Surg Pak 15: 528-531.

22. Thomopoulos KC, Labropoulou-Karatza C, Mimidis KP, Katsakoulis EC, Iconomou G, et al. (2003) Non-Invasive Predictors of the Presence of Large Oesophageal Varices in Patients with Cirrhosis. Dig Liver Dis 35: 473-478.

23. Montasser MF, Abdella HM, Samy AH (2014) Evaluation of Venous Ammonia Level, Splenic Longitudinal Diameter, Portal Vein and Splenic Vein Diameters as Non-Invasive Indicators for the Presence of Portosystemic Collaterals in Egyptian Cirrhotic Patients. Open j gastroenterol 4: 265-274.

24. Qamar AA, Grace ND, Groszmann RJ, Garcia-Tsao G, Bosch J, et al. (2000) Platelet count is not a predictor of the presence or development of Gastroesophageal varices in cirrhosis. Hepatology 47: 153-159. 